\title{
Is the Sac Waiting to Rupture? Sinus of Valsalva Aneurysm
}

\author{
Ankur Phatarpekar, MD, DM*, Milind Phadke, MD, DM, Charan Lanjewar, MD, DM, FACC, FESC, \\ Prafulla Kerkar, MD, DM, FACC, FESC, FSCAI
}

Department of Cardiology, Seth Gordhandas Sunderdas Medical College and King Edward VII Memorial Hospital, Mumbai, India

\begin{abstract}
Completely asymptomatic sinus of Valsalva aneurysms are rare entities, and there is no consensus regarding their management. We present the case of a patient who underwent atrial septal defect device closure at 5 years of age and was lost to follow-up, then presented 6 years later with unruptured sinus of Valsalva aneurysm and was closely followed. The aneurysm eventually ruptured and was successfully operated on with good outcomes.

Copyright @ 2016 Science International Corp.
\end{abstract}

\section{Key Words}

Unruptured sinus of Valsalva aneurysm - Atrial septal defect • Amplatzer device.

\section{Case Presentation}

An asymptomatic 11-year-old male presented for a routine evaluation. At the age of 5 years, he had undergone transcatheter closure (TCC) with a 16-mm Amplatzer Septal Occluder (ASO) (St. Jude Medical, St. Paul, MN, USA) for an atrial septal defect (ASD) with adequate rims except for a deficient aortic rim. Five months after the procedure, he underwent a clinical and echocardiographic follow-up that revealed normalization of the right heart chamber dimensions, ASO in situ straddling the aorta due to deficient aortic rim, and no residual interatrial shunting. Since then, the patient had felt well and had not sought any follow-up medical services.

Fax +1 2037853552

E-Mail: aorta@scienceinternational.org

http://aorta.scienceinternational.org

\author{
(c) 2016 AORTA \\ Published by Science International Corp. \\ ISSN 2325-4637 \\ Accessible online at: \\ http://aorta.scienceinternational.org
}

Physical examination was unremarkable. Electrocardiogram (ECG) showed sinus rhythm with incomplete right bundle branch block, which was also seen in earlier ECGs. The PR interval was $0.14 \mathrm{~s}$. Chest $X$-ray was normal. ECG showed a large saccular unruptured sinus of Valsalva aneurysm (SOVA) from the noncoronary sinus (NCS) of the aorta and protruding into the right atrium (RA), measuring $1.5 \mathrm{~cm}$ at the aortic end and $2 \mathrm{~cm}$ at the RA end, without any other associated lesions and not causing any obstruction (Figure $1 \mathrm{~A}$ ). The ASO was seen in situ without residual interatrial shunting. There was good distance between the two defects, the right atrial site of SOVA being lower than the anteroinferior margin of the ASD rim. The left ventricular function was normal. Computerized tomography (CT) scan was used to better profile the aneurysm (Figure 1B). Due to his asymptomatic status and lack of compressive features, such as conduction blocks, valvular regurgitation, or obstruction, the patient was asked to follow-up every 3 months. On follow-up, the size of the aneurysm was unchanged as assessed by ECG. After about 1 year, the patient developed acute gastroenteritis with severe frequent bouts of vomiting and cough with breathlessness. On physical examination there was a grade $3 / 6$ continuous murmur heard best in the $3 \mathrm{rd} / 4$ th parasternal area with signs of right heart failure. ECG showed the rupture of SOVA with the aneurysm draining from NCS to RA causing severe RA and right ventricular volume overload and pericardial effusion (Figure 1C). Because TCC of this aneurysm was not feasible due to the large aortic end of the sac measuring $1.5 \mathrm{~cm}$, the patient was

\footnotetext{
* Corresponding Author:

Ankur Phatarpekar, MD, DM

Department of Cardiology

Seth Gordhandas Sunderdas Medical College \& King Edward VII Memorial Hospital

4th Floor, CVTC Bldg, E. Borges Rd, Parel, Mumbai 400 012, India

Tel.: +91 222410 7636; Fax: +91 222411 6732; E-Mail: drankurmd@gmail.com
} 


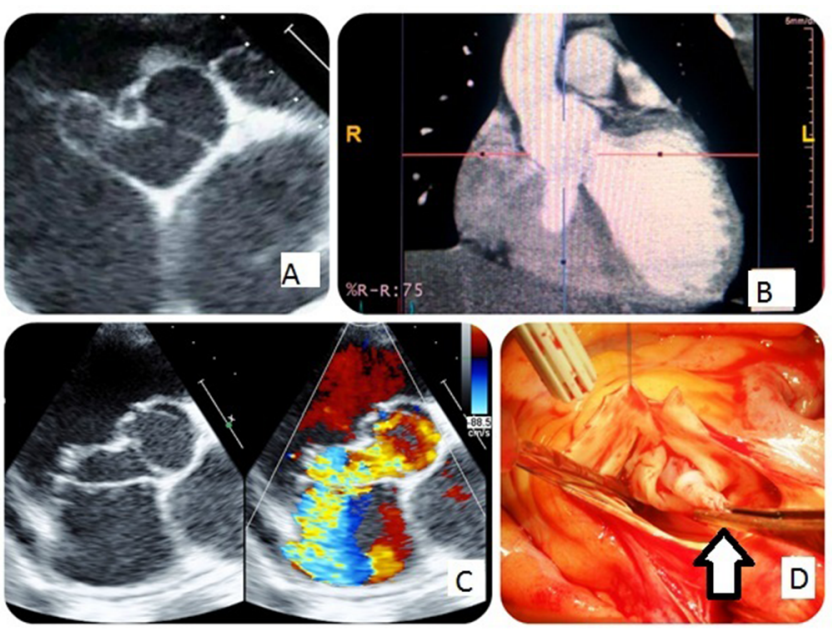

Figure 1. Images showing the unruptured sinus of Valsalva that eventually ruptured and required surgery. Panel $A$. Echocardiogram image of the sac of the unruptured sinus of Valsalva in high basal short-axis view, the sinus extends from the noncoronary cusp into the right atrium. Panel B. Computed tomography image of the same unruptured sac from the aorta into the right atrium. Panel C. The color compare echo image showing the typical "windsock" appearance of the ruptured sinus of Valsalva and the color image showing blue flow from the aorta into the right atrium. Panel D. Intraoperative image. An aortotomy was performed, and the right atrium end of the sac was everted out of the incision and held with the forceps (arrow).

sent for surgery. The aorta was opened obliquely above the NCS. The ruptured SOVA sac was excised and closed with Sauvage filamentous dacron and pericardial patch on cardiopulmonary bypass (Figure 1D).

\section{Discussion}

SOVA is a rare cardiac anomaly that may be either acquired or congenital. A congenital lack of continuity between the aortic media and annulus fibrosis may initiate aneurysm formation. Less frequently, infections or degenerative processes may affect the aortic wall. SOVA is associated with multiple lesions, most commonly a ventricular septal defect. Rarely, SOVA may be associated with an ASD and staged TCC of both defects has been described [1]. SOVA may rupture into an extra- or intracardiac location [1]. Unruptured SOVA may cause right ventricular outflow tract obstruction, infective endocarditis, malignant arrhythmias, or myocardial ischemia/infarction due to severe distortion of coronary ostia or compression of the coronary trunks and conduction blocks [2]. The natural history of untreated, ruptured SOVA has a mean survival period of 3.9 years [3], so early surgery is indicated in such cases. Surgical intervention is also necessary in unruptured SOVA when the patient is symptomatic or there is evidence of obstruction or compression. Optimal management of asymptomatic, unruptured aneurysm is uncertain as no precise natural history is currently available. It is tempting to attribute the development of SOVA to the TCC of ASD procedure in our patient, especially because the aortic rim of the ASD was deficient. Intraoperatively, an indentation of ASO was noticed on the inner aspect of the aorta. However, the base of the aneurysm was away from the inferior rim of the device. It is possible that the mechanical force of the ASO may have distorted the aortic root, resulting in the development of the SOVA. In our patient, it might be attributable to a congenital weakness at the junction of the aortic media and annulus fibrosis. Indeed, device traction on the NCS has been hypothesized to cause aortic regurgitation following TCC of ASD [4], although this has been debated [5].

Vural et al. [5] described a detailed approach to SOVA, based on the clinical picture and the echocardiographic findings. In asymptomatic cases, surgery is indicated if the size of the aneurysm is larger than $50 \%$ of the average size of the other two normal Valsalva sinuses or is increasing in consecutive ECG examinations. This approach, however, is not based on any background data. The rationale for not surgically intervening in asymptomatic SOVA is the morbidity and mortality associated with the procedure itself. On long-term follow-up, a number of surgically operated patients require re-intervention for recurrence of SOVA rupture and aortic valve replacement for significant aortic valve regurgitation [6].

On the other hand, asymptomatic SOVA may expand, causing more severe symptoms and requiring more extensive corrective procedures in the future. Recent surgical advancements have significantly reduced mortality associated with the procedure. A "wait and watch" asymptomatic SOVA policy is therefore questioned by some authors [7]. Nevertheless, our case illustrates that conservatively managed asymptomatic SOVA needs careful follow-up with high anticipation for the diagnosis of rupture and prompt treatment. 


\section{Conflict of Interest}

\section{Comment on this Article or Ask a Question}

The authors have no conflict of interest relevant to this publication.

\section{References}

1. Mehta NK, Mishra N, Kerkar P. Percutaneous closure of ruptured sinus of valsalva aneurysm and atrial septal defect. J Invasive Cardiol. 2010;22:E82-E85. PMID: 20440051

2. Kerkar P. Ruptured sinus of Valsalva aneurysm: yet another hole to plug! Ann Pediatr Cardiol. 2009;2:83-84. DOI: 10.4103/09742069.52818

3. Moustafa S, Mookadam F, Cooper L, Adam G, Zehr K, Stulak J, et al. Sinus of Valsalva aneurysms -47 years of a single center experience and systematic overview of published reports. Am J Cardiol. 2007;99:1159-1164. DOI: 10.1016/j. amjcard.2006.11.047
4. Schoen SP, Wiedeman S, Bock M, Kappert $\mathrm{U}$, Strasser RH. Interatrial septal closure devices and aortic perforation: a note of caution. J Invasive Cardiol. 2009;21: E39-E41. PMID: 19182304

5. Vural KM, Sener E, Taşdemir O, Bayazit K. Approach to sinus of Valsalva aneurysms: a review of 53 cases. Eur J Cardiothorac Surg. 2001;20:71-76. DOI: 10.1016/S10107940(01)00758-8

6. van Son JA, Danielson GK, Schaff HV, Orszulak TA, Edwards WD, Seward JB. Long-term outcome of surgical repair of ruptured sinus of Valsalva aneurysm. Circulation. 1994;90:II20-II29. PMID: 7955253
7. Takach TJ, Reul GJ, Duncan JM, Cooley DA, Livesay JJ, Ott DA, et al. Sinus of Valsalva aneurysm or fistula: management and outcome. Ann Thorac Surg. 1999;68:1573-1577. DOI: 10.1016/S00034975(99)01045-0

Cite this article as: Phatarpekar A, Phadke M, Lanjewar C, Kerkar P. Is the Sac Waiting to Rupture? Sinus of Valsalva Aneurysm. AORTA (Stamford). 2016;4(3):105-107. DOI: http://dx.doi. org/10.12945/j.aorta.2016.15.027 